\title{
AVALIAÇÃO DE PARÂMETROS FíSICO-QUÍMICOS DA ÁGUA DO CÓRREGO DA ONÇA, TRÊS LAGOAS - MS
}

\author{
Juliana Heloisa Pinê Américo ${ }^{1}$
}

Letícia de Oliveira Manoel $^{2}$

Nádia Hortense Torres ${ }^{3}$

\begin{abstract}
RESUMO
O Córrego da Onça atravessa o município de Três Lagoas - MS e ao longo do seu percurso sofre interferências da urbanização e da pastagem, além de receber o efluente da Estação de Tratamento de Esgoto do município (ETE). Objetivou-se monitorar durante doze meses os parâmetros físicoquímicos de temperatura, $\mathrm{pH}$ e concentração de oxigênio dissolvido na água do Córrego da Onça, afim de avaliar a qualidade da sua água. Seis pontos foram amostrados. A concentração de oxigênio dissolvido (OD) e a determinação da temperatura foram realizadas in situ com auxílio de oximetro, enquanto que o $\mathrm{pH}$ foi determinado em laboratório com auxílio de pHmetro de bancada. Os valores obtidos foram comparados aos definidos na Resolução CONAMA 357/05. As maiores temperaturas da água foram registradas no mês de dezembro e oscilaram entre 32 e $37^{\circ} \mathrm{C}$. Os valores de $\mathrm{pH}$ apresentaram seus níveis abaixo da neutralidade, sendo que estes coincidem com os meses de maior precipitação. A concentração de OD variou entre os pontos ao longo do córrego desde $0 \mathrm{mg} \mathrm{L}^{-1}$ no ponto localizado na jusante da ETE até $12,2 \mathrm{mg} \mathrm{L}^{-1}$ na Lagoa do Meio. O ponto que recebe efluente da ETE teve o pH e OD alterados em relação aos demais. Na maioria dos meses, nesse ponto os parâmetros avaliados não se enquadraram no padrão estabelecido pela legislação indicando a influência da ETE na qualidade da água.
\end{abstract}

PALAVRAS-CHAVE: Monitoramento. Oxigênio dissolvido. Temperatura.

\section{PARAMETERS ASSESSMENT PHYSICAL AND CHEMICAL ONÇA STREAM OF WATER, TRÊS LAGOAS - MS}

\begin{abstract}
The Stream of Onça runs through the municipality of Três Lagoas - MS and along your route suffers interference of urbanization and grazing, in addition to receiving the effluent from municipal sewage treatment plant (WWTP). The objective was to monitor for twelve months, the physicochemical parameters of temperature, $\mathrm{pH}$ and dissolved oxygen concentration in the water Stream of Onça in order to assess the quality of your water. Six points were sampled. The concentration of dissolved oxygen (DO) and the determination of the temperature were performed in situ with the aid oximeter,

\footnotetext{
${ }^{1}$ Doutoranda em Aquicultura do Centro de Aquicultura da UNESP, Jaboticabal - SP. E-mail: americo.ju@gmail.com

${ }^{2}$ Mestre em Engenharia Civil - Recursos Hídricos e Tecnologias Ambientais, Faculdade de Engenharia de Ilha Solteira (FEIS/UNESP). E-mail:leticia.is@gmail.com

${ }^{3}$ Pós-doutoranda, Universidade Tiradentes (Unit), Aracajú - SE. E-mail: nadiahortense@gmail.com
} 


\section{Periódica Eletrânica \\ Fórum Ambiental}

da Alta Paulista
Volume 11, Número 06, 2015

Planejamento e Gestão dos Recursos Hídricos

while the $\mathrm{pH}$ was determined in the laboratory bench with the aid of pHmeter. The values obtained were compared to those defined in CONAMA Resolution 357/05. The highest water temperatures were recorded in December and fluctuated between 32 and $37^{\circ} \mathrm{C}$. The $\mathrm{pH}$ values presented their below-neutrality, and these coincide with the months of highest precipitation. The DO concentration ranged between points along the stream from $0 \mathrm{mg} \mathrm{L}^{-1}$ in the point located at the downstream of WWTP to $12.2 \mathrm{mg} \mathrm{L}^{-1}$ in Middle Pond. The point that receives WWTP effluent had $\mathrm{pH}$ and OD changed in relation to the other. In most months, at which point the evaluated parameters did not fit the pattern established by law indicating the influence of WWTP in water quality.

PALAVRAS-CHAVE: Monitoring. Dissolved oxygen. Temperature.

\section{PARÁMETROS FÍSICOS DE EVALUACIÓN Y QUÍMICAS EM CORRIENTE DE AGUA DE LA ONÇA, TRÊS LAGOAS - MS}

\section{RESUMO}

El arroyo de la Onça pasa por el municipio de Três Lagoas - MS ya lo largo de su ruta sufre interferencias de la urbanización y el pastoreo, además de recibir el efluente de la planta de tratamiento de aguas residuales municipales (PTAR). El objetivo era monitorear durante doce meses, los parámetros físico-químicos de la temperatura, el pH y la concentración de oxígeno disuelto en el agua corriente de $\mathrm{Oz}$ con el fin de evaluar la calidad de su agua. Seis puntos se tomaron muestras. La concentración de oxígeno disuelto (DO) y la determinación de la temperatura se lleva a cabo in situ con el oxímetro de ayuda, mientras que el pH se determinó en el banco de laboratorio con la ayuda de pH metro. Los valores obtenidos se compararon con los definidos en la Resolución CONAMA 357/05. Las temperaturas más altas de agua se registraron en diciembre y fluctuaron entre 32 y $37^{\circ} \mathrm{C}$. Los valores de pH por debajo presentaron su neutralidad, y éstos coinciden con los meses de mayor precipitación. La concentración de OD varió entre los puntos a lo largo de la corriente de $0 \mathrm{mg} \mathrm{L}^{-1}$ en el punto situado en la corriente abajo de ETE a $12,2 \mathrm{mg} \mathrm{L}^{-1}$ en la charca de Oriente. El punto que recibe PTAR efluente tenía pH y OD cambió en relación con el otro. En la mayoría de los meses, momento en el que los parámetros evaluados no se ajustaban al modelo establecido por la ley que indica la influencia de la PTAR en la calidad del agua.

PALAVRAS-CHAVE: Seguimiento. Oxígeno disuelto. Temperatura.

\section{INTRODUÇÃO}

Embora dependam da água para sobrevivência e para o desenvolvimento econômico, as sociedades humanas poluem e degradam este recurso. A diversificação dos usos múltiplos, o despejo de resíduos líquidos e sólidos nos ambientes aquáticos relacionados ao crescimento populacional e ao grau de urbanização tem provocado contínua e sistemática degradação e perdas elevadas em quantidade e qualidade da água (TUNDISI, 2003).

A preocupação com a degradação dos recursos hídricos e as perspectivas de escassez faz com que seja necessária uma interpretação eficaz da qualidade das águas. Portanto, torna-se necessária a utilização de poucos e significativos parâmetros que permitam avaliar e monitorar, de forma objetiva e adequada, a qualidade dos recursos hídricos (DONADIO et al., 2005). 
Vários processos podem influenciar a qualidade da água de um manancial, ou seja, qualquer alteração na bacia hidrográfica pode ocasionar alterações significativas nas características físicas, químicas e biológicas da água. Essas características são indicadores da saúde do ecossistema aquático, que podem ser utilizadas para o controle e o monitoramento das atividades desenvolvidas em uma bacia hidrográfica (MARGALEF, 1994).

O Córrego da Onça é um exemplo de corpo hídrico que está sujeito à intensa degradação da qualidade de sua água. Este córrego atravessa o município de Três Lagoas - MS e ao longo do seu percurso sofre interferências da urbanização e da pastagem, além de receber o efluente da Estação de Tratamento de Esgoto (ETE) do município.

Assim, o objetivo desse trabalho foi monitorar durante doze meses os parâmetros físico-químicos de temperatura, $\mathrm{pH}$ e concentração de oxigênio dissolvido na água do Córrego da Onça, município de Três Lagoas, Estado do Mato Grosso do Sul, afim de avaliar por meio desses parâmetros a qualidade da água desse corpo hídrico.

\section{MATERIAL E MÉTODOS}

O município de Três Lagoas está localizado na porção leste do Estado do Mato Grosso do Sul, com vegetação característica de cerrado e mata atlântica. Possui uma população de 89.493 habitantes e uma área de unidade territorial de 10.206,37 km2 (INSTITUTO BRASILEIRO DE GEOGRAFIA E ESTATISTICA- IBGE, 2009).

O Córrego da Onça, localizado nesse município, esta sujeito há anos à intensa degradação da qualidade de sua água em função do despejo inadequado de esgoto sanitário, além do aporte de substâncias provindas do sistema de drenagem urbano somado a degradação física, tanto do solo quanto de sua vegetação original, devido ao aproveitamento da área da bacia para atividades urbanas e pastoris de forma desordenada.

Considerando a problemática desse ambiente, realizou-se um plano de monitoramento nesse corpo hídrico que obteve dados de doze meses consecutivos, no período de outubro de 2008 a setembro de 2009, a fim de se avaliar a sua 
degradação. Seis pontos devidamente georreferenciados foram amostrados, estes denominados: (P1) Lagoa do Meio; (P2) Lagoa Maior; (P3) Final da Canalização; (P4) Jusante da Estação de Tratamento de Esgoto (ETE); (P5) Novas Nascentes e (P6) Foz. A Figura 1 apresenta a localização dos pontos de coleta da Bacia Hidrográfica do Córrego da Onça, Três Lagoas - MS com uma área de $125 \mathrm{~km}^{2}$ (MOREIRA, 2006).

Figura 1: Localização dos pontos de amostragem na Bacia Hidrográfica do Córrego da Onça, Três Lagoas - MS

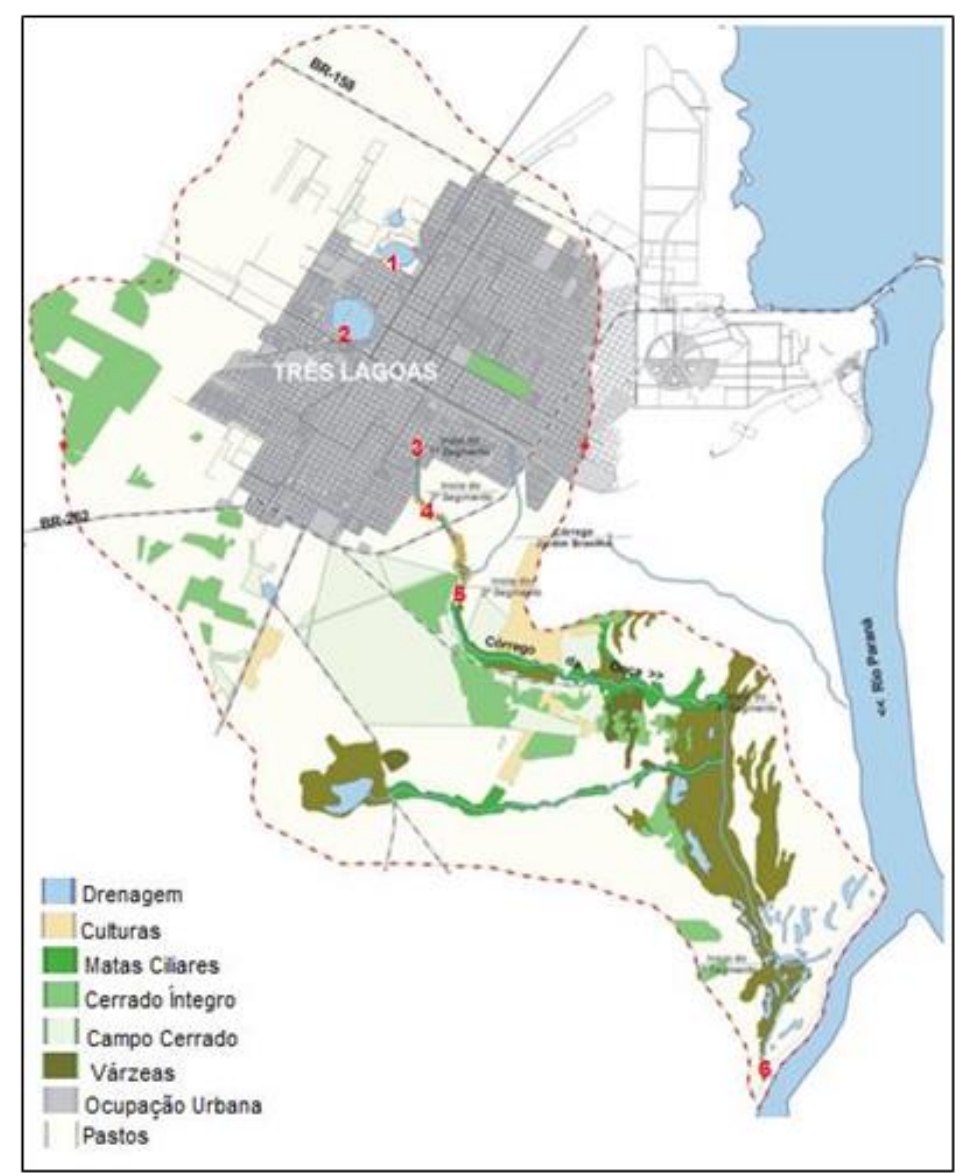

Fonte: MOREIRA, 2006.

As quantificações da concentração de oxigênio dissolvido e determinação da temperatura dos pontos de amostragem foram realizadas in situ com auxílio de Oximetro HI 9146-04 - Hanna Instruments, enquanto que do pH foi determinado em laboratório com auxílio de pHmetro de bancada Digiped.

Os resultados obtidos foram comparados aos valores definidos na Resolução CONAMA n 357 de 17 de março de 2005. 


\section{RESULTADOS E DISCUSSÃO}

O Córrego da Onça - MS não dispõe de uma classificação de suas águas. Assim, de acordo com a resolução CONAMA 357/05, em seu capitulo VI Artg. 42 "enquanto não aprovados os respectivos enquadramentos, as aguas doces serão consideradas classe 2". Utilizou-se esta classificação com a finalidade de analisar as condições em que se encontra o córrego estudado.

As maiores temperaturas da água foram registradas no mês de dezembro e oscilaram entre 32 e $37^{\circ} \mathrm{C}$. A menor temperatura deste mês foi encontrada no P6 enquanto que a maior ocorreu no P1 e P2 que se localizam em área urbanizada. Os menores valores de temperatura ocorreram no mês de junho e variaram de 22,3 a $25^{\circ} \mathrm{C}$. A temperatura media da água em cada ponto de coleta durante os meses de monitoramento estão apresentadas na Tabela 1.

Tabela 1: Temperaturas médias do período de Outubro de 2008 a Setembro de 2009 , em ${ }^{\circ} \mathrm{C}$, nos locais de coleta do Córrego da Onça - MS

\begin{tabular}{ccccccc}
\hline & Pontos Amostrais \\
\cline { 2 - 7 } & P1 & P2 & P3 & P4 & P5 & P6 \\
\hline $\begin{array}{c}\text { Temperatura } \\
\text { Média }\end{array}$ & 29,7 & 29,4 & 28,2 & 27,4 & 27,5 & 24,7 \\
\hline
\end{tabular}

De acordo com a Resolução CONAMA 357/05 as águas doces de classe 2 devem possuir $\mathrm{pH}$ ente 6 e 9 . O P5 teve $75 \%$ de suas amostras com $\mathrm{pH}$ menor que 6 , neste local o parâmetro variou de 5 a 6,27 enquanto que no P3 e P6 todas as amostras se enquadraram no padrão estabelecido. No que diz respeito ao P4 (Jusante da ETE), nem todas as amostras se enquadraram na legislação apesar dos dados do efluente da ETE em relação a este parâmetro estarem conforme o padrão permitido pelo CONAMA 357/05.

Considerando-se a variação do $\mathrm{pH}$ nos pontos amostrais durante os meses de monitoramento, e os dados de precipitação obtidos, observa-se que os valores de pH encontrados no córrego apresentaram seus níveis abaixo da neutralidade, sendo que estes coincidem com os meses de maior precipitação. 
Assim, é provável que a entrada de matéria orgânica, associada ao carreamento via precipitação tenha contribuído com estes menores valores de $\mathrm{pH}$; com exceção para o P3, no qual registrou-se dois casos com valores acima da neutralidade. Os valores médios de $\mathrm{pH}$ nos pontos de coleta são demonstradas na Tabela 2.

Tabela 2: Valores médios de pH do período de Outubro de 2008 a Setembro de 2009, nos locais de coleta do Córrego da Onça - MS

\begin{tabular}{lllllll}
\hline & \multicolumn{7}{c}{ Pontos Amostrais } \\
\cline { 2 - 7 } & P1 & P2 & P3 & P4 & P5 & P6 \\
\hline pH & 6,4 & 6,4 & 6,8 & 6,2 & 5,5 & 6,2 \\
\hline
\end{tabular}

A concentração de oxigênio dissolvido (OD) variou expressivamente entre os pontos ao longo do Córrego da Onça - MS desde $0 \mathrm{mg} \mathrm{L}^{-1}$ no ponto localizado na jusante da ETE (P4) até 12,2 $\mathrm{mg} \mathrm{L}^{-1}$ na Lagoa do Meio (P1).

Segundo CONAMA 357/05, a concentração de OD, em qualquer amostra, não pode ser inferior a $5 \mathrm{mg} \mathrm{L}^{-1}$ em corpos d'agua classificados como 2. Das doze amostras coletadas no P5, onze delas apresentaram uma concentração abaixo do padrão estabelecido. Este ponto localizado em afloramentos de água registrou valores menores possivelmente porque há grande quantidade de matéria orgânica de origem vegetal presente na água que durante sua decomposição pode estar consumindo o oxigênio dissolvido no meio.

No P4 apenas três das doze amostras apresentaram concentração de OD igual ou superior a $5 \mathrm{mg} \mathrm{L}^{-1}$. Este fato poderia estar relacionado a não eficiência da ETE na remoção de DBO, no entanto os dados fornecidos pela ETE de Três Lagoas - MS se enquadram no padrão de lançamento de efluente estabelecido pela legislação.

Assim, uma possível explicação tanto para a concentração de OD inferior a 5 $\mathrm{mg} \mathrm{L}^{-1}$ quanto para o $\mathrm{pH}$ não adequado é a vazão quase nula (principalmente nos meses de estiagem) do canal do córrego onde o efluente é lançado que não permite uma diluição adequada do efluente.

As baixas concentrações de OD (menores que $5 \mathrm{mg} \mathrm{L}^{-1}$ ) também encontradas em P1, P2 e P3 podem ser resultado das possíveis ligações clandestinas de esgoto 
sanitário sem tratamento presente neste pontos. A concentração media de OD em cada ponto de amostragem e apresentada na Tabela 3.

Tabela 3. Concentração média de OD, em $\mathrm{mg} \mathrm{L}^{-1}$, do período de Outubro de 2008 a Setembro de 2009, nos locais de coleta do Córrego da Onça - MS

\begin{tabular}{lllllll}
\hline & \multicolumn{7}{c}{ Pontos Amostrais } \\
\cline { 2 - 7 } & P1 & P2 & P3 & P4 & P5 & P6 \\
\hline OD & 5,3 & 5,6 & 5,3 & 3,4 & 1,7 & 4,0 \\
\hline
\end{tabular}

Ressalta-se que durante o estudo houve um período (Janeiro/09) em que as concentrações de OD apresentaram-se menores $\left(<3,2 \mathrm{mg} \mathrm{L}^{-1}\right)$ em relação ao padrão observado. Esta situação pode estar associada ao elevado índice pluviométrico mensal registrado, que possivelmente favoreceu o aporte de material orgânico que promoveu o consumo de oxigênio no corpo hídrico.

\section{CONCLUSÃO}

Por meio dos resultados obtidos pode-se concluir que os parâmetros de $\mathrm{pH} \mathrm{e}$ oxigênio dissolvido na água variaram ao longo do Córrego da Onça - MS. O ponto do corpo hídrico que recebe o efluente da ETE do município teve $\mathrm{opH}$ e a concentração de oxigênio dissolvido alterados em relação aos demais. Na maioria dos meses, nesse ponto os parâmetros avaliados não se enquadraram no padrão estabelecido pelo CONAMA 357/05 indicando a influência da ETE na qualidade da água.

Baixas concentrações de oxigênio dissolvido (menores que $5 \mathrm{mg} \mathrm{L}^{-1}$ ) podem prejudicar a sobrevivência de algumas espécies aquáticas e alterar o equilíbrio e biodiversidade do ambiente. 


\section{REFERÊNCIAS}

CONSELHO NACIONAL DO MEIO AMBIENTE - CONAMA. Resolucao n`357, de 17 de marco de 2005. Disponivel em: <http:www.mma.gov.br/port/conama> Acesso: 15 maio. 2009.

DONADIO, N. M. M.; GALBIATTI, J. A.; PAULA, R. C. Qualidade da água de nascentes com diferentes usos do solo na Bacia Hidrográfica do Córrego Rico, São Paulo, Brasil. Engenharia Agrícola, v.25, p.115-125, 2005.

INSTITUTO BRASILEIRO DE GEOGRAFIA E ESTATISTICA- IBGE. Cidades@: Tres Lagoas MS. [S.I.: sn.], 2009. Disponivel em: <http://www.ibge.gov.br/cidadesat/default.php>. Acesso: 19 dez. 2009.

MARGALEF, R. The place of epicontinetal waters in global ecology. In: MARGALEF, R. Limnology now: a paradigm of planetary problems. Amsterdam: Elsevier Science, 1994. p.1-8.

MOREIRA, M. A. L. 2006. As molduras vegetais do Córrego da Onça: Tres Lagoas, Mato Grosso do Sul. 2006. 72f. Trabalho de Conclusao de Curso (Graduacao em Geografia)- Departamento de Ciencias Humanas, Universidade Federal de Mato Grosso do Sul- UFMS, Tres Lagoas, 2006.

TUNDISI, J.G. Água no século XXI: enfrentando a escassez. 2.ed. São Carlos: RIMA, 2003, 248p. 